\title{
EDITORIAL
}

\section{POR QUE PESQUISAR?}

Ouvem-se reflexões, sobre o quanto representa, entre a população brasileira que trabalha, a grande parcela constituída pelo pessoail de enfermagem.

São em número de 155998 os cadastrados no Conselho Federal de Enfermagem, até 30 de setembro de 1983. Sabe-se que se todos os atendentes de enfermagem fossem incluídos o número seria muito maior. Seu cadastramento obrigatório foi interrompido em 1978.

Para fins de raciocínio com detalhe, consideremos o número de enfermeiros (26720) e obtetrizes (472), que totalizam 27192 profissionais.

Há serviços de enfermagem em todas as Unidades da Federação. Estão eles satisfatórios para a população que recebe os serviços, para o pessoal que os presta, para outros em atividade nesses serviços, isto é, satisfazem também àqueles médicos e outros, cujas ações, em comparação com as do pessoal de enfermagem, estão em interdependência?

Meditemos: o XXXV Congresso Brasileiro de Enfermagem e a Assembléia de Delegados da ABEn, reunidos em São Paulo, nos últimos sete dias de setembro deste ano, sem dúvida deram uma demonstração de pujança e valor do grupo de profissionais de enfermagem. Em suas reuniões estiveram representados todos os Estados e o Distrito Federal. Uma reflexão ocorre, neste momento. Supondo que pudéssemos conhecer em realidade e claramente, o estado de todas as instituições de saúde deste grande e multiforme País que é o nosso, teriam respostas afirmativas as perguntas formuladas linhas atrás?

Poderiam as pessoas que trabalham nos serviços de enfermagem, somados com outros que estão nos órgãos de direção, e com os que estão em serviços com ações entrosadas e interdependentes em relação às de enfermagem, poderiam tais pessoas tomar medidas novas e melhorar os serviços de saúde?

Uma grande alavanca para começar-se a mudar seria o conhecimento do que está acontecendo. Sem pesquisarmos não poderemos ir para diante, progredir, em termos de serviços melhores.

Nas cidades em que há curso de graduação em enfermagem e obstetrícia, e, principalmente, naqueles em que há curso de pós-graduação em enfermagem, o órgão normativo de uma instituição de saúde local ou sua diretoria ou conselho poderia recorrer a enfermeiros habilitados entregando-lhes o encargo de pesquisarem os fatos principais e recomendarem medidas para a melhoria dos serviços de enfermagem. Por outro lado, os recursos financeiros gastos pelas instituições de saúde, para tal investigação, conquanto modestos, poderiam injetar reforço nas verbas atualmente limitadas dos centros de formação de pessoal. Valerá a pena o empenho em pesquisa. Os que sabem estão declarando: sem investigação científica nosso País não progredirá. Vamos para a frente? (HGD) 